\title{
Community variations in social vulnerability to Cascadia-related tsunamis in the U.S. Pacific Northwest
}

\author{
Nathan J. Wood $\cdot$ Christopher G. Burton $\cdot$ Susan L. Cutter
}

Received: 30 December 2008/ Accepted: 2 March 2009/Published online: 26 March 2009

(C) The Author(s) 2009. This article is published with open access at Springerlink.com

\begin{abstract}
Tsunamis generated by Cascadia subduction zone earthquakes pose significant threats to coastal communities in the U.S. Pacific Northwest. Impacts of future tsunamis to individuals and communities will likely vary due to pre-event socioeconomic and demographic differences. In order to assess social vulnerability to Cascadia tsunamis, we adjust a social vulnerability index based on principal component analysis first developed by Cutter et al. (2003) to operate at the census-block level of geography and focus on community-level comparisons along the Oregon coast. The number of residents from blocks in tsunami-prone areas considered to have higher social vulnerability varies considerably among 26 Oregon cities and most are concentrated in four cities and two unincorporated areas. Variations in the number of residents from census blocks considered to have higher social vulnerability in each city do not strongly correlate with the number of residents or city assets in tsunami-prone areas. Methods presented here will help emergency managers to identify community sub-groups that are more susceptible to loss and to develop riskreduction strategies that are tailored to local conditions.
\end{abstract}

Keywords Social vulnerability $\cdot$ SoVI $\cdot$ Cascadia $\cdot$ Tsunami · Oregon · Principal component analysis

N. J. Wood $(\bowtie)$

Western Geographic Science Center, U.S. Geological Survey, 1300 SE Cardinal Court, Bldg. 10, Vancouver, WA 98683, USA

e-mail: nwood@usgs.gov

C. G. Burton · S. L. Cutter

Hazards and Vulnerability Research Institute, Department of Geography, University of South Carolina, Columbia, SC 29208, USA

C. G. Burton

e-mail: burton@mailbox.sc.edu

S. L. Cutter

e-mail: scutter@sc.edu 


\section{Introduction}

The 2004 Great Sumatra-Andaman earthquake in the Indian Ocean raised global awareness of the vulnerability of coastal populations to tsunamis. One of the most significant tsunami threats in the United States is a tsunami related to an earthquake generated within the Cascadia subduction zone (CSZ), the interface of the North American and Juan de Fuca tectonic plates extending more than 1,000 km from northern California to southern British Columbia (Fig. 1; Atwater 1987; Rogers et al. 1996; Satake et al. 1996). A future CSZrelated earthquake is capable of generating a series of tsunami waves possibly $8 \mathrm{~m}$ or higher that could inundate the nearby U.S. Pacific Northwest coast in fifteen to thirty minutes after initial ground shaking (Oregon Department of Geology and Mineral Industries 2008; Cascadia Region Earthquake Workgroup 2005; Walsh et al. 2003; Priest et al. 2001; Myers et al. 1999). Although much has been done to improve tsunami-hazard awareness (Bernard 2005; Oregon Department of Geology and Mineral Industries 2007; Priest et al. 1996) and tsunami-warning systems in this region (Gonzales et al. 2005; McCreery 2005), less has been done to understand community vulnerability to tsunamis, specifically the potential impacts on people and infrastructure (U.S. Government Accountability Office 2006). Given the catastrophic potential and quick arrival times of tsunamis generated by local CSZ earthquakes, emergency managers must understand who is vulnerable to tsunamis so that they can prepare realistic and effective evacuation and response procedures for individuals in tsunami-prone areas.

Vulnerability as a science involves examining the combination of physical, social, economic, and political components that influence the degree to which an individual, community, or system is threatened by a particular event, as well as their ability to mitigate these threats and recover if the event was to occur (Cutter 2001, 2003; Cutter et al. 2000; Mileti 1999; Hewitt 1997; Wisner et al. 2004). Although definitions and applications of the term vulnerability vary (Cutter 1996; Weichselgartner 2001), common elements within the natural hazard's literature include concepts of exposure, sensitivity, and resilience (Cutter et al. 2006; Cutter 2003; Dow 1992; Hewitt 1997; Turner et al. 2003). Exposure is related to hazard proximity and the environmental characteristics of a place, while sensitivity and resilience are characteristics of an individual, group, or socioeconomic system. Sensitivity refers to differential degrees of potential harm and the ability of an individual or community to protect itself from future events (Cutter et al. 2006), while resilience addresses an individual's or community's coping and adaptive capacities during and after an extreme event (Adger et al. 2005; Tobin 1999; Turner et al. 2003). Given equal exposure to external environmental threats, two groups may vary in their sensitivity and resilience due to internal societal characteristics.

Previous studies of societal vulnerability to CSZ-related tsunamis have largely focused on critical facilities (Charland and Priest 1995; Lewis 2007), perception studies (Johnston et al. 2005; Johnston et al. 2007; Wood and Good 2005), and local case studies (Wood et al. 2002; Wood and Good 2004). Regional comparisons of community exposure to Cascadia-related tsunamis on the Oregon coast (Wood 2007) and the open-ocean coast of Washington (Wood and Soulard 2008) indicate that tens of thousands of people live, work, and play in areas likely to be inundated by CSZ-related tsunamis. A significant portion of these individuals may require assistance in preparing for and responding to a tsunami. For example, $45 \%$ of the residents in the tsunami-prone areas of the City of Bandon, Oregon, are over 65 years in age (Wood 2007), and these older residents may have difficulty in evacuating, given the predicted 30 min between initial CSZ earthquake ground shaking and subsequent tsunami inundation. In addition to age, Wood (2007) identifies other 


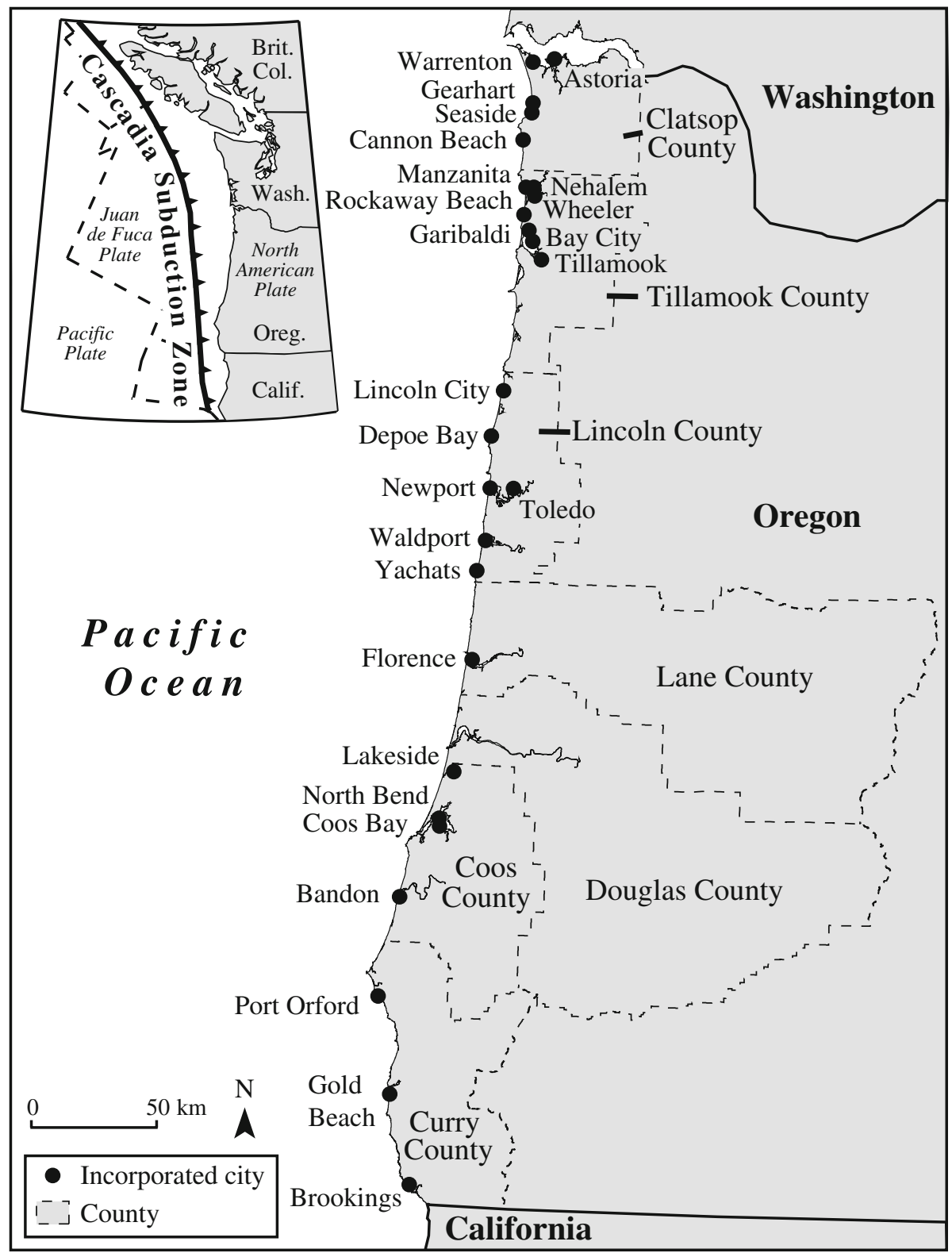

Fig. 1 Oregon cities with land in a tsunami-hazard zone related to Cascadia earthquakes plus an inset map showing the extent of the Cascadia subduction zone

demographic attributes of exposed populations considered indicators of social vulnerability, such as gender, race, and socioeconomic status (Cutter 2001; Cutter et al. 2003; Tierney et al. 2001; Wisner et al. 2004).

Assessing community vulnerability through an inventory of demographic attributes, such as those presented in Wood (2007), will help managers identify isolated issues of 
vulnerability (e.g., an elderly population needing assistance to evacuate quickly), but it fails to address how multiple demographic characteristics of an individual or neighborhood interact and likely amplify each other. The vulnerability of an individual who is living below the poverty level, elderly, and unable to speak the primary language is likely much larger than just the result of each attribute taken in isolation. The same can be said at the community level, where one neighborhood may be significantly more vulnerable if it contains high concentrations of single-parent, low-income, and poorly-educated populations living in close proximity to each other. Therefore, to appreciate the complex nature of social vulnerability, emergency managers need methods to understand the multivariate characteristics of individuals and communities in tsunami-prone areas.

One approach to quantify the multivariate nature of a population is the use of exploratory factor analysis, a data-reduction technique that has been widely used in humangeography research (Clark et al. 1974, 1998; Mather and Openshaw 1974; Scott 1975). Principal component analysis (PCA), one of the most common multivariate factorial approaches, uncovers the underlying dimensions of a large set of variables and mathematically transforms data into a smaller set of components based on intercorrelated variables. Specific to demographic data, the social vulnerability index (SoVI) is a spatially based descriptive tool that uses PCA to compare social vulnerability between places and has largely focused on county-level assessments (Boruff et al. 2005; Boruff and Cutter 2007; Cutter et al. 2003; Cutter and Finch 2008). Although a CSZ-related tsunami is a regional hazard that threatens thousands of people across three U.S. states and in British Columbia, Canada, a traditional county-level SoVI application is inappropriate because the majority of residents in many coastal counties are not in predicted tsunami zones; for example, only $4 \%$ of residents in Oregon coastal counties are in CSZ-related, tsunamiprone areas (Wood 2007).

In this article, we present an approach designed to describe the multivariate nature of individuals living in areas prone to CSZ-related tsunami inundation and to determine which communities have high concentrations of populations with potentially higher social vulnerability. We adjust the SoVI approach to operate at the census-block level of geography and concentrate only on residents in the tsunami-inundation zone, allowing us to examine variations in the demographic sensitivity of exposed populations. Focusing on the Oregon coast, we extend the use of the SoVI by calculating the number and percentage of total residents in each city with tsunami-prone land that are in census blocks considered to have higher relative social vulnerability, allowing us to comment on regional spatial patterns in vulnerability. Within this context, we explore several spatial properties of vulnerability including: (1) the multidimensional nature of residents in a well-defined hazard zone that spans several communities, (2) a method to determine which communities have elevated concentrations of higher socially vulnerable populations, and (3) insight into whether these concentrations relate to city attributes (e.g., total number of residents in tsunami-prone areas). Information and methods presented here further the dialogue on understanding societal risk to tsunami hazards and can be used by emergency managers to augment regional risk-reduction strategies with site-specific efforts that reflect local conditions and needs.

\section{Study area}

This study focuses on the seven coastal counties of Oregon, including Clatsop, Tillamook, Lincoln, Lane, Douglas, Coos, and Curry, and the 26 incorporated cities (based on 2005 
city-limit boundaries) within them that intersect a statewide, potential tsunami-inundation zone (Oregon Geospatial Enterprise Office 2008) (Fig. 1). There are also 12 unincorporated towns along the Oregon coast, as delineated by census-designated place boundaries (U.S. Census Bureau 2005) that intersect the tsunami-inundation zone. Since emergency services and land-use planning for unincorporated towns are performed by county offices, results related to these towns are reported at the county level.

The tsunami-inundation zone was developed by the Oregon Department of Geology and Mineral Industries (DOGAMI) to support the implementation of a statewide ordinance (Oregon Revised Statute 455.446-447), limiting the construction of critical facilities in tsunami-prone areas (Olmstead 2003). Based on geologic evidence of past events and tsunami-propagation modeling, the tsunami-inundation zone delineates the upper limit of area expected to be covered by flood water from a tsunami caused by a magnitude 8.8 CSZ earthquake (Priest 1995). The intent of the inundation zone of Priest (1995) was to map the most likely CSZ tsunami flooding for the entire Oregon coast for use in building code enforcement. Later case studies (e.g., Witter 2008; Witter et al. 2007; Zhang et al. 2007) explored a larger range of potential CSZ tsunamis for a variety of uses, including worstcase events for evacuation planning, but these studies did not produce an inundation zone for the entire Oregon coast.

\section{Methods}

The purpose of this analysis is to understand relationships between the various types of residents living in the Oregon tsunami-inundation zone and to identify communities with the highest concentrations of residents that may have higher social vulnerability. Due to the limited spatial extent of the predicted tsunami-inundation zone, we adjust the SoVI, an exploratory factor analysis originally designed at the county level, to use census blocks, which are the smallest geographic units used in the decennial population count of the U.S. Census Bureau. The SoVI is based on the use of PCA to reduce a large number of census variables into a smaller set of multivariate components where variable members of each component exhibit similar variation across the study area, and each component explains a certain amount of the total variance of the entire dataset.

In the original SoVI derivation, a principal component analysis was conducted for all U.S. counties ( $n=3,141)$ using 42 socioeconomic, demographic, and built environment variables that were selected based on empirical post-disaster research (Cutter et al. 2003). The county-level PCA produced eleven components that explained $76 \%$ of the variance, where components relating to personal wealth and age were the greatest contributors to the variance (Cutter et al. 2003). SoVI scores for each county were derived by adding PCA loadings for each component of a county and are reported in terms of standard deviations from the study area mean, where higher scores suggest higher social vulnerability. Since PCA is a data-reduction technique, components and subsequent SoVI scores are dependent on selected input variables and relevant only to the database from which the PCA was conducted (Burton and Cutter 2008).

For our adaptation of the SoVI to the census-block level, we first selected all census blocks from the 2000 U.S. Census (U.S. Census Bureau 2008) that are completely contained within or overlap the Oregon tsunami-inundation zone. Blocks with zero population would improperly distort a PCA and were therefore removed from the data, leaving 2,083 census blocks for analysis. Of the 42 census variables used in the original SoVI derivation, the following 29 variables were considered to be appropriate for a block-level PCA 
analysis as it relates to the ability of individuals to evacuate tsunami-prone areas before inundation (e.g., mobility) and to recover after a Cascadia tsunami (e.g., access to resources):

- Age, including median age, percentage under five years of age, percentage over 65 years of age, number of nursing home residents per capita, and percentage of population 25 or older with less than 12 years education;

- Employment, including percentage of civilian labor force participation, percentage of civilian unemployment, percentage employed in primary industry, farming, fishing, mining, and forestry, percentage employed in transportation, communication, and other public utilities, and percentage employed in service occupations;

- Gender, including percentage of females, percentage of households that are female headed, and percentage of female labor force participation;

- Housing, including average number of persons per household, percentage of occupied housing units that are renters, percentage of housing units as mobile homes, percentage of population living in urban areas, and percentage of population living on rural farms;

- Race and ethnicity, including percentage of population that is Black or African American, percentage of population that is American Indian or Alaska Native, percentage of population that is Asian, percentage of population that is Hispanic or Latino, and percentage of population resulting from international migration; and

- Socioeconomic status, including per capita income, percentage of families earning $\$ 100,000$ or more, percentage of persons living in poverty, percentage of people receiving Social Security benefits, median home value, and median rent.

For variables only available at the block-group level (e.g., the percentage of civilian labor force unemployed), we assumed all blocks had the same percentage as their larger block-group. Thirteen variables from the original SoVI derivation were excluded because they define community attributes, such as (1) local and regional economies, including the number of manufacturing establishments per square mile, the number of commercial establishments per square mile, earnings of all industries per square mile, general local government debt to revenue ratio, and value of all non-residential property, (2) medical services, including the number of hospitals per capita and the number of physicians per 100,000 population, (3) political context, including voting records, and (4) regional population growth, including birth rate, the number of new housing permits, percent decennial population change, and housing density.

All data for the 2,083 blocks were then standardized through conversion to " $z$ scores" resulting in zero means and unit variances. $Z$-scores are derived by subtracting the mean of the study area from the block value and then dividing this difference by the standard deviation for the study area. The use of standardized $z$-scores avoids potential errors resulting from the aggregation of variables with different means (Jones and Andrey 2007). A PCA was then conducted on the standardized $z$-scores relating to 29 block-level variables. We used the PCA procedure to minimize the number of individual variables loading high on a single component, while at the same time, increasing the differences between the components. A varimax rotation and Kaiser Criterion (eigenvalues greater than 1) were used for extracting significant loadings to minimize the number of variables that load high on a single component which, in turn, increases the percentage of variation between each component (Cutter et al. 2003). We consider component loadings for an individual census variable to be significant at 0.5 and higher or -0.5 and lower. Once the component loadings were derived, adjustments were made to their directionality with respect to their known influences on vulnerability, based on the empirical literature on what increases or 
decreases social vulnerability (Cutter et al. 2003). A positive directionality was assigned to all components believed to increase vulnerability (e.g., poverty), while a negative directionality was assigned to all components believed to decrease vulnerability (e.g., wealth) (Cutter et al. 2003). Component scores are then added to yield a composite SoVI score for each block. Since negative and positive components are added, resulting SoVI scores should be considered to only approximate the collective vulnerability of a block, as they implicitly assume that potentially unrelated disadvantages of one group in a block will theoretically be compensated with an advantage of another group. Although compensatory logic is assumed with metrics that use linear aggregation, more research is needed to determine whether this is a valid assumption when assessing social vulnerability (Jones and Andrey 2007).

In the original SoVI, component scores were equally weighted within its additive model. This was considered appropriate at the county levels because of the lack of justification for explicit weights or well-established relationships between variables (Jones and Andrey 2007) and because counties contained significant populations with high demographic variability. However, scale-dependent deficiencies may exist at the smaller block level when focusing on a region where the PCA-based SoVI metric may inappropriately focus on isolated anomalies or outliers within individual blocks and not on significant regional trends. This could be a function of a rotated factor analytic approach, where the varimax rotation focuses on such outliers and represents them within dimensions that explain a miniscule amount of variance. In an effort to minimize this potential deficiency and more accurately represent those components that contribute the most to demographic variability within the region, we weighted each component score by its percentage of variance explained, thereby forcing components with higher variance to contribute more to the overall SoVI score (Piegorsch et al. 2007; Schmidtlein et al. 2008). Once all blocks had a weighted SoVI score, a mean and standard deviation were calculated for the region and blocks were classified in units of standard deviation from the mean (identical to the $z$-score transformation described earlier). Mapping via standard deviations provides a relative representation of which blocks deviate more from regional means (Borden et al. 2007) and does not provide an absolute representation of vulnerability where we can say that block $\mathrm{X}$ is twice as vulnerable as block Y.

In order to compare the social vulnerability of Oregon coastal cities, census blocks with SoVI scores greater than one standard deviation from the mean were classified as having high social vulnerability and the number of residents in these blocks was summed for each of the 26 incorporated cities on the Oregon coast, as well as the unincorporated portions of the 7 coastal counties. Slivers of census-block polygons that overlap administrative boundaries and tsunami zones were omitted and final population counts are adjusted proportionately. The number of residents from census blocks considered to have high social vulnerability in each community was calculated to determine if these populations are distributed uniformly across the study area and comprise similar percentages of total population in each community. If they are not and this population is concentrated in a subset of communities, emergency managers may wish to target these communities with additional preparedness planning efforts.

These calculations are not meant to imply that we consider all individuals in census blocks with high SoVI scores to have high social vulnerability; doing so would constitute an ecological fallacy. The SoVI analysis is a relative, regional assessment based on attribute percentages (e.g., percent of individuals living in mobile homes); therefore, not all individuals within a census block with a high SoVI score may have high social vulnerability. We calculate the number of individuals in census blocks with high SoVI scores for 
each city only to better understand the relative magnitude of social vulnerability as it varies among cities. Like the SoVI analysis itself, these calculations are for comparative purposes only and should not be considered exhaustive inventories of individuals with high social vulnerability.

A subsequent question to knowing the number of residents in each community that is in census blocks with high SoVI scores is whether these populations correlate to certain community attributes (e.g., city size, total number of residents in the tsunami-hazard zone). If this is the case, then the level of social vulnerability within each community may simply be a reflection of the size of the exposed population or other assets. In order to test whether or not the number of residents in blocks with high SoVI scores correlate to various city attributes, simple linear regressions were conducted where the dependent variable was the number of individuals from census blocks considered to have high social vulnerability in the tsunami-hazard zone of each city and the independent variables were the total number of people, the amount of developed land, total parcel values, and total number of employees in the tsunami-hazard zone (data from Wood 2007). These attributes are chosen based on the data U.S. jurisdictions are encouraged to collect as they develop local hazardmitigation plans (Federal Emergency Management Agency 2001), a requirement to qualify for funds under the U.S. Hazard Mitigation Grant Program in accordance with the Disaster Mitigation Act of 2000, Public Law 106-390. The null hypothesis in each test is that no statistically significant relationship exists.

All residents in the predicted tsunami-inundation zone can be considered vulnerable in some way to the tsunami threat. However, our adaptation and extension of the SoVI approach provides emergency managers with a method for determining which demographic characteristics are spatially correlated and where there are high concentrations of more vulnerable populations. Once a census block is considered to have a high SoVI score or a community is considered to have a high number of residents from blocks with high SoVI scores, emergency managers can then look at individual PCA components, as well as the original census variables, to determine where residents with potentially higher social vulnerability may exist and why they may have higher social vulnerability relative to a future tsunami.

\section{Components of social vulnerability}

A principal components analysis of populated census blocks in the Oregon tsunami-hazard zone results in 11 broad components that explain $64.6 \%$ of the variance (Table 1; Fig. 2). These 11 components and the census-block variables they each represent are summarized under five overarching demographic themes-wealth and education, age and tenancy, employment and housing, gender, and race. Since the analysis is based on $z$-scores (i.e., distance in standard deviations from the study-area mean), these components identify the variables that exhibit the highest amount and similar trends in variability (covariance) across the study area. The intent of this analysis is to determine which variables exhibit similar patterns of variability across the study area, and then to discuss their relevance to community vulnerability to CSZ-related tsunami hazards.

\subsection{Wealth and education}

The first component represents $9.7 \%$ of the database variance and captures four variables that relate to wealth and education (Table 1). Variable loadings in this component suggest 
Table 1 Vulnerability components with Eigen values, the percentage variance explained by that component, and the primary census variables of each component, based on a principal component analysis with a varimax rotation

\begin{tabular}{|c|c|c|c|}
\hline Component & Eigenvalue & $\begin{array}{l}\% \text { of } \\
\text { variance }\end{array}$ & Primary census variables and component loadings \\
\hline $\begin{array}{l}\text { 1. Wealth and } \\
\text { education }\end{array}$ & 2.814 & 9.704 & $\begin{array}{l}\text { Per capita income }(0.897) \\
\text { Percent families earning } \$ 100,000 \text { or more }(0.807) \\
\text { Percent persons } 25 \text { or older with less than } 12 \text { years } \\
\quad \text { education }(-0.550) \\
\text { Percent persons living in poverty }(-0.614)\end{array}$ \\
\hline 2. Age and tenancy & 2.723 & 9.389 & $\begin{array}{l}\text { Percent under five years of age }(0.673) \\
\text { Average number of persons per household }(0.639) \\
\text { Percent renter occupied housing units }(0.551) \\
\text { Percent over } 65 \text { years of age }(-0.697) \\
\text { Median age }(-0.875)\end{array}$ \\
\hline 3. Urban/rural & 2.310 & 7.965 & $\begin{array}{l}\text { Percent of the population living in urban areas }(0.794) \\
\text { Percent employed in service occupations }(0.548) \\
\text { Percent employed in primary industry, farming, fishing, } \\
\text { mining, and forestry }(-0.520) \\
\text { Percent rural farm populations }(-0.641)\end{array}$ \\
\hline 4. Housing & 1.929 & 6.652 & $\begin{array}{l}\text { Percent housing units as mobile homes }(0.566) \\
\text { Percent employed in transportation, communication, } \\
\text { and other public utilities }(0.553) \\
\text { Median dollar value of owner occupied housing units } \\
\quad(-0.693)\end{array}$ \\
\hline $\begin{array}{l}\text { 5. Labor force } \\
\text { participation }\end{array}$ & 1.805 & 6.225 & $\begin{array}{l}\text { Percent civilian labor force participation }(0.796) \\
\text { Percent social security recipients }(-0.883)\end{array}$ \\
\hline $\begin{array}{l}\text { 6. Immigration and } \\
\text { female workers }\end{array}$ & 1.567 & 5.404 & $\begin{array}{l}\text { Percent international migration }(0.688) \\
\text { Percent female labor force participation }(-0.743)\end{array}$ \\
\hline 7. Median rent & 1.200 & 4.139 & Median rent $(0.838)$ \\
\hline $\begin{array}{l}\text { 8. Females and nursing } \\
\text { homes }\end{array}$ & 1.164 & 4.014 & $\begin{array}{l}\text { Percent females }(0.672) \\
\text { Nursing home residents per capita }(0.612)\end{array}$ \\
\hline $\begin{array}{l}\text { 9. Female-headed } \\
\text { households }\end{array}$ & 1.097 & 3.781 & Percent female headed households $(0.860)$ \\
\hline $\begin{array}{l}\text { 10. Race (African- } \\
\text { American) }\end{array}$ & 1.085 & 3.743 & $\begin{array}{l}\text { Percent Black or African American }(0.798) \\
\text { Percent civilian unemployment }(0.506)\end{array}$ \\
\hline 11. Race (Asian) & 1.045 & 3.605 & $\begin{array}{l}\text { Percent Asian }(0.713) \\
\text { Percent American Indian or Alaska Native }(-0.660)\end{array}$ \\
\hline
\end{tabular}

that neighborhoods do not have a wide range of income levels (i.e., individuals with high incomes are not in the same census blocks as those living under the poverty line) and that whether an individual has attained a high-school diploma is related to personal wealth. In general, the Oregon tsunami-hazard zone can be characterized as having low- to middleincome households, based on results that indicate that the percentage of families earning $\$ 100,000$ or more in this zone is approximately half the national average (5.7\% compared to $10.7 \%$, respectively) and the percentage of individuals living in poverty here approximates the national average ( $12.8 \%$ compared to $12.7 \%$, respectively). The percentage of 


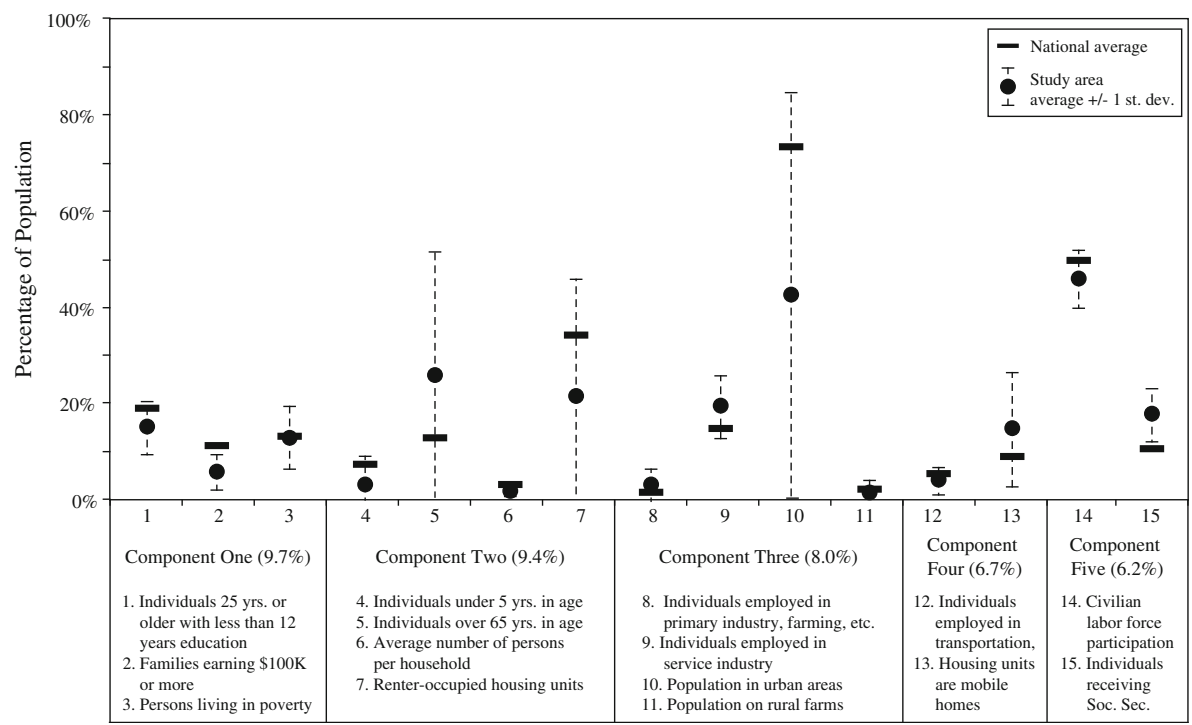

Fig. 2 Demographic characteristics of Oregon residents in the predicted tsunami-inundation zone, including study area and national averages. Demographic attributes are organized by components determined by principal component analysis, where component percentages signify the percentage of the overall study-area variance

individuals in the tsunami-hazard zone that are older than 25 years in age and lack a highschool diploma is slightly less than the national average $(15.0 \%$ compared to $18.5 \%$, respectively) (Fig. 2). The reference and comparison to national averages in this and subsequent component descriptions is meant to provide context and perspective for demographic attributes that are highlighted by the PCA because of their high variability within the study area.

With regards to social vulnerability, low-income households are often impacted greater by extreme events than high-income households. Structural maintenance and mitigation initiatives are often out of reach for low-income households, and homes may therefore sustain greater damage following a significant event due to the nature of the housing stock (Burton and Cutter 2008; Cochrane 1975; Morrow 1999; Wisner et al. 2004). In addition, low-income households often have insufficient financial reserves for buying services and materials following an event (Morrow 1999); therefore, economic recovery after a catastrophic tsunami may be more difficult.

\subsection{Age and tenancy}

The second component represents $9.4 \%$ of the study-area variance and includes five variables that relate to age and household tenancy (Table 1). Variable loadings on this component suggest that neighborhoods with high numbers of young children are associated with higher numbers of people per household and higher numbers of renter-occupied households, but not high numbers of older residents. Relative to national averages, the study area has low percentages of children under 5 years in age (3.17\% compared to $6.8 \%)$, low percentages of renter-occupied housing (21.5\% compared to $33.8 \%)$, and low numbers of individuals per household (1.6 compared to 2.59)—all indicators of relatively lower 
social vulnerability (Fig. 2). Although tsunami-zone percentages are low compared to national averages, the neighborhoods with children and renter-occupied households are considered to have higher social vulnerability because renters are less likely than homeowners to prepare for catastrophic events (Burby et al. 2003) and families with many dependents are likely to encounter greater obstacles when responding to an emergency due to limited financial reserves and the coupling of work responsibilities and care for family members (Cutter et al. 2003; H. John Heinz III Center for Science, Economics and the Environment 2000; Morrow 1999). The percentage of individuals 65 years in age or older in the Oregon tsunami-hazard zone is more than double the national average $(25.7 \%$ and $12.4 \%$, respectively). Research suggests the older populations may require assistance in evacuation due to potential mobility and health issues or a reluctance to evacuate, may require special medical equipment at shelters (McGuire et al. 2007), and are more apt to lack social and economic resources to recover (Morrow 1999; Ngo 2003). It may be difficult to quickly evacuate older populations from tsunami-prone areas along the Oregon coast, given their potential health and mobility issues and the limited time between earthquake ground-shaking and tsunami inundation. In addition, if a tsunami was to occur during the winter months, emergency shelters may not be equipped to adequately protect older populations from exposure to low air temperatures and high precipitation (common during winter months on the Oregon coast), causing further health complications.

\subsection{Employment and housing}

The third, fourth, fifth, and seventh components collectively represent variables relating to differences in employment and housing across the study area and indicate that certain occupations are associated with certain landscapes and housing arrangements across the study area (Table 1). Component 3 represents $8.0 \%$ of the study-area variance and suggests that urban neighborhoods are associated with individuals working in service industries, while rural areas are associated with individuals working in the natural resources, such as farming, fishing, mining, and forestry. Component 4 represents $6.7 \%$ of the study-area variance and suggests that neighborhoods with high percentages of mobile homes, regardless of whether they are in urban or rural settings, contain high percentages of individuals employed in transportation, communication, and other public utilities. Component 5 represents $6.2 \%$ of the study-area variance and suggests an inverse relationship between individuals in the laborforce and those receiving social security benefits. Relative to national averages, the study area has high percentages of individuals with natural resources-related occupations $(3.1 \%$ in the study area compared to $0.9 \%$ for the nation), with service-related occupations $(19.3 \%$ compared to $14.3 \%$ ), living in mobile homes (14.7\% compared to $8.4 \%$ ) and receiving social security benefits (17.7\% compared to $9.9 \%$ ). Study-area percentages are slightly lower than national averages for civilian labor force participation (45.8\% compared to $49.3 \%$ ) and for employment in transportation, communication, and other public-utility sectors $(4.0 \% \mathrm{com}$ pared to $4.9 \%$ ) (Fig. 2). The relatively high percentages of mobile homes, recipients of socialsecurity benefits, lower income service and natural-resource occupations, and relatively low percentage of civilian labor-force participation all indicate high socially vulnerable populations along the Oregon coast.

\subsection{Gender}

Several components reflect gender-related variations at the census block level (Table 1). Representing $5.4 \%$ of the study-area variance, variables in component 6 suggest areas with 
high international migration have low female participation in the labor force. Component 8 represents $4.0 \%$ of the study-area variance and indicates a correlation between the percentage of females and the number of nursing home residents per capita. Component 9 represents $3.8 \%$ of the study-area variance and includes a positive loading on the percentage of female-headed households. Past research of gender differences to natural hazards indicates that although women tend to have higher risk perceptions, demonstrate higher preparedness planning, and are more likely to respond to warnings than men, they are more likely to be single parents or primary care givers and have lower incomes, fewer financial resources, and less autonomy than males (Bateman and Edwards 2002; Enarson and Morrow 1998; Laska and Morrow 2007). Although gender-related variations are considered by the PCA to be moderately significant among individual census blocks in the Oregon tsunami-hazard zone, a comparison of the study-area and national averages of the original block variables suggest that gender-related variables are not significant issues for the entire region. The percentage of female-headed households in the Oregon tsunamihazard zone is approximately one-third of the national average $(3.7 \%$ and $12.0 \%$, respectively). The percentage of international migration in the study area is approximately half of the national average ( $25.8 \%$ compared to $46.3 \%$, respectively). Study-area averages are similar to national averages for the percentage of females (both 51.0\%) and for the percentages of female labor force participation $(47.4 \%$ and $46.9 \%$, respectively). The comparison of study-area averages to national averages of these gender-related demographic attributes suggest that these attributes may amplify social vulnerability within individual census blocks, but are not dominant vulnerability trends for the entire study area.

\subsection{Race and ethnicity}

The tenth and eleventh components both relate to variations based on race and ethnicity (Table 1). Race and ethnicity influence individual sensitivity to natural hazards due to historic patterns of racial and ethnic inequalities within the U.S. that result in minority communities which lack resources to prepare and mitigate (Cutter et al. 2003), and are more likely to have inferior public services, infrastructure, and building stock (Laska and Morrow 2007), and that may be excluded from disaster planning efforts (Morrow 1999). The tenth component represents $3.7 \%$ of the study-area variance, and variable loadings suggest that neighborhoods with higher percentages of Black or African-American residents are associated with higher percentages of civilian unemployment. The eleventh component represents $3.6 \%$ of the study-area variance and variable loadings suggest that residents who classify themselves as Asian and as American Indian or Alaska Native are not associated with the same neighborhoods. Although variations based on race at the census-block level are considered moderately significant by the principal component analysis, the Oregon tsunami-inundation zone does not have high racial diversity- $96 \%$ of all residents identified themselves in the 2000 Census as White, either alone or in combination with one or more other races (Wood 2007). Only $0.27 \%$ of residents in the study area classify themselves as Black or African American, compared to $12.8 \%$ for the nation. The percentage of residents who classify themselves as Asian in the study area is low and are one-third of the national average ( $1.32 \%$ compared to $4.4 \%$, respectively). The percentage of residents who classify themselves as American Indian or Alaska Native is $1.24 \%$, comparable to the national average of $1.0 \%$. Therefore, race and ethnicity may be amplifying components within individual census blocks and for certain individuals but are not significant vulnerability trends for the entire region. 


\section{Geographic variations in social vulnerability}

The crux of social vulnerability research is the assumption that certain groups are likely to suffer disproportionately following a damaging event due to differences in wealth, history, and sociopolitical organization (Wisner et al. 2004). In order to effectively reduce societal risks from catastrophic hazards, mitigation and emergency managers must understand (1) the social characteristics that give rise to the vulnerabilities within the communities they protect, and (2) the spatial patterns of social vulnerability across a region. Answering both questions will help managers identify the individuals and communities that may be more susceptible to loss or possibly lack the ability to recover quickly following a catastrophic event. Results of the PCA analysis in the previous section help to address the first question and suggest that although the predicted Oregon tsunami-inundation zone contains over 22,000 residents (Wood 2007), the potential impacts of a CSZ-related tsunami will likely vary among these individuals due to observed differences in wealth, education, age, etc., across the study area.

Mapping via SoVI scores allows one to determine where there are potential hotspots of social vulnerability within a community, and then determine what the primary components at a particular location are. For example, a map of census blocks classified by SoVI $z$-scores for the City of Seaside allows managers to quickly identify where potential hotspots may exist, including the census blocks labeled A and B (Fig. 3). Blocks A and B both contain ten individuals and may be considered to have higher social vulnerability (SoVI scores greater than 1.0) possibly due to the high percentages of residents in these blocks who are over 65 years in age (50\% and $70 \%$, respectively) and likely amplified by the high percentage of females ( $80 \%$ in block B) and of renters (12.5\% in block A).

In order to examine spatial patterns of social vulnerability between communities, we determined how many residents in the tsunami-prone areas of each community are in census blocks with high SoVI scores. For the purposes of this case study, we define high social vulnerability populations as those residing in census blocks with transformed SoVI $z$-scores greater than 1.0 (i.e., greater than one standard deviation from the regional mean). Overall, there are 2,044 individuals in census blocks who are considered to have high social vulnerability, representing $9 \%$ of all residents in the Oregon tsunami-hazard zone. The number of residents in the tsunami-hazard zone from blocks considered to have high social vulnerability is not constant among Oregon communities, as $76 \%$ of these individuals come from only four incorporated cities (Seaside, Lincoln City, Waldport, and Warrenton) and the unincorporated portions of two counties (Tillamook and Coos) (Fig. 4a). At the community level, there is no discernible geographic trend for where these populations are located, as high concentrations occur on the northern (e.g., City of Seaside), central (e.g., City of Lincoln City), and southern (e.g., unincorporated portions of Coos County) sections of the Oregon coast.

There is also no apparent relationship between the number of residents considered to have high social vulnerability (Fig. 4a) and the percentage they represent of the total number of residents in the tsunami-hazard zone (Fig. 4b). For example, the City of Seaside has the highest number of residents considered to have higher social vulnerability (422), but this group only represents $9 \%$ of the in-hazard population. Similar communities with high amounts but low percentages of the total in-hazard population include the cities of Warrenton, Lincoln City, and Waldport and the unincorporated portions of Clatsop, Tillamook, and Coos counties. In these communities, emergency managers may overlook these special needs populations that are large in numbers, but represent a small fraction of the total population that could be impacted by a tsunami. Conversely, there are several 


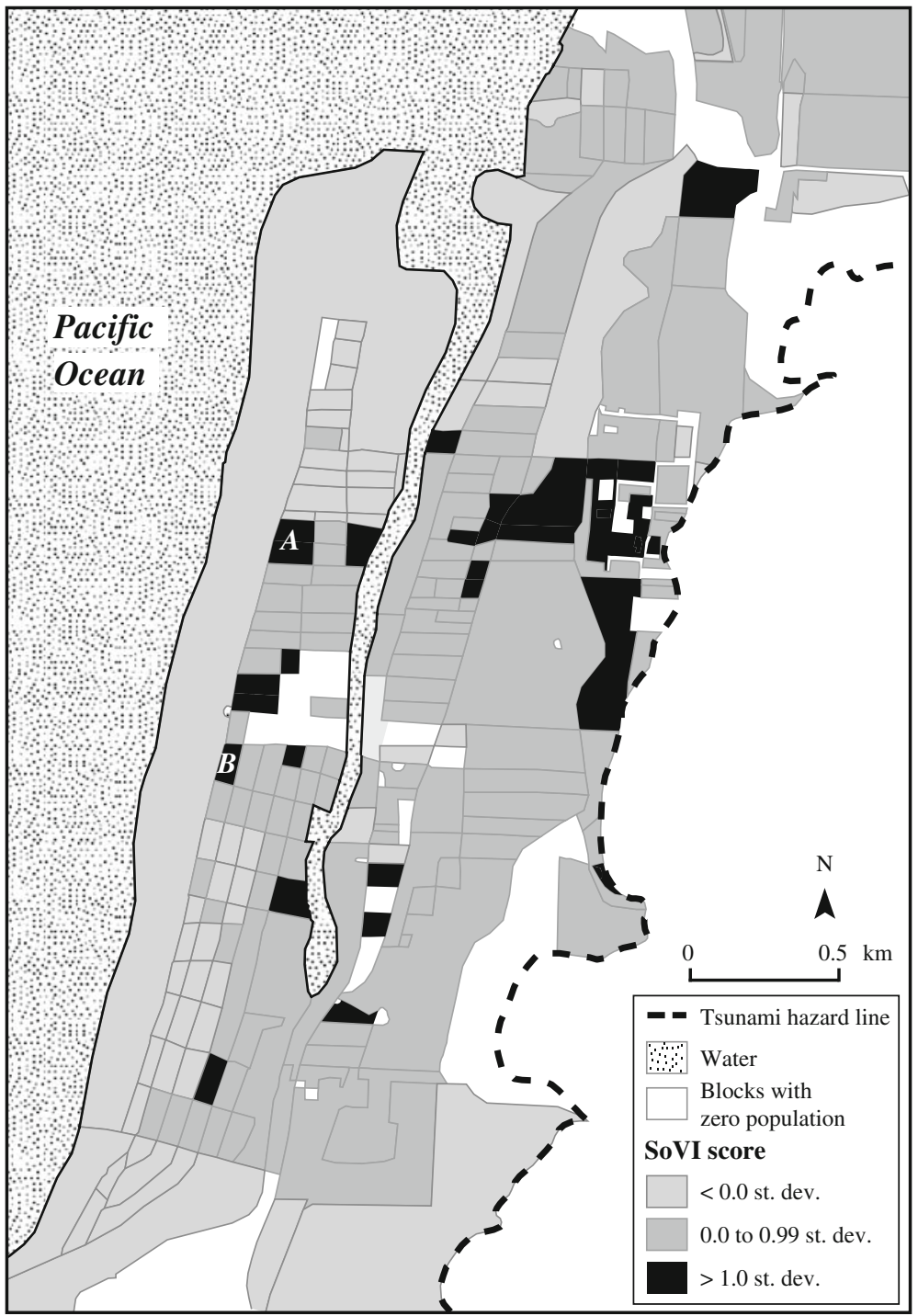

Fig. 3 Map of census blocks, classified by SoVI scores, in the City of Seaside, Oregon. SoVI scores are classified in standard deviations from the mean. Blocks labeled A and B in the figure are considered to have higher relative social vulnerability than other blocks in the study area and are further discussed in the text

communities, such as the cities of Astoria, Nehalem, Wheeler, Toledo, and Bandon, which have low numbers of residents from blocks with high SoVI scores, but these few individuals represent high percentages of the in-hazard population (Fig. 4). In these communities, emergency managers will be assisting small, but disproportionately highly vulnerable, populations.

Simple linear regressions were conducted to determine if the number of individuals from blocks considered having higher social vulnerability in each community correlates to certain city-level attributes (defined in Wood 2007). The dependent variable was the 


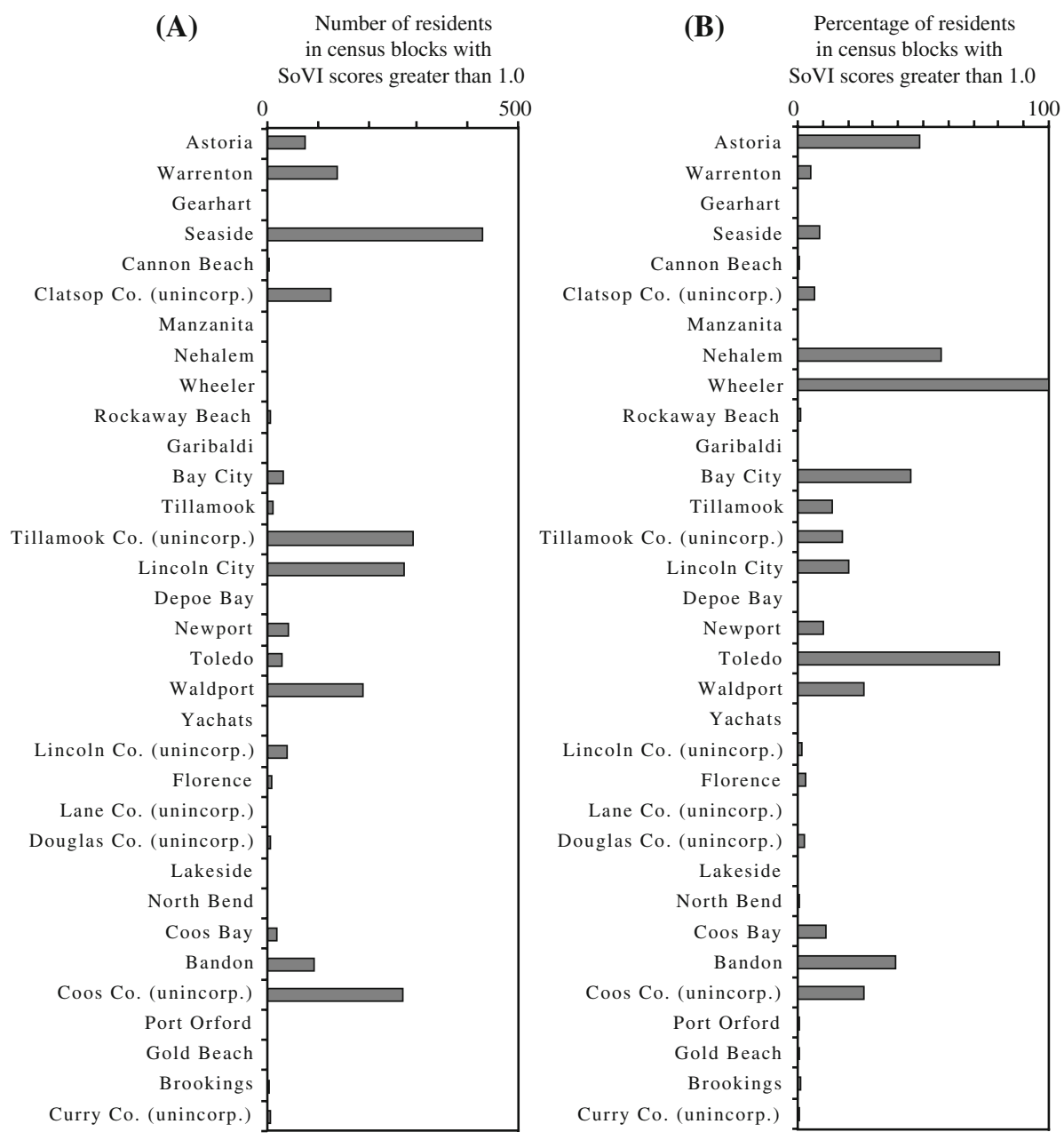

Fig. 4 The number (a) and percentage (b) of individuals in the tsunami-hazard zone from census blocks with SoVI $z$-scores greater than 1.0

number of residents from census blocks with SoVI scores greater than 1.0 and the independent variables were the number of residents, the amount of developed land, total parcel values, and the number of employees in the predicted tsunami-inundation zone (all from Wood 2007). All relationships are statistically significant (all have $p<0.01$ ) but are not particularly strong based on moderate explained variance $\left(r^{2}\right)$ values, including total amount of developed land $\left(r^{2}=0.594\right)$, total number of residents $\left(r^{2}=0.584\right)$, total number of employees $\left(r^{2}=0.409\right)$, and total amount of parcel values $\left(r^{2}=0.390\right)$ in the tsunami-inundation zone. For example, Fig. 5 graphically portrays how the number of individuals in a city's predicted tsunami-inundation zone is not a strong indicator of the number of individuals that can be considered to have high social vulnerability. Therefore, these city attributes cannot be considered a strong indicator on their own for the number of individuals in blocks who may have high social vulnerability in a community in this study area. These findings support the need for emergency managers to determine local 


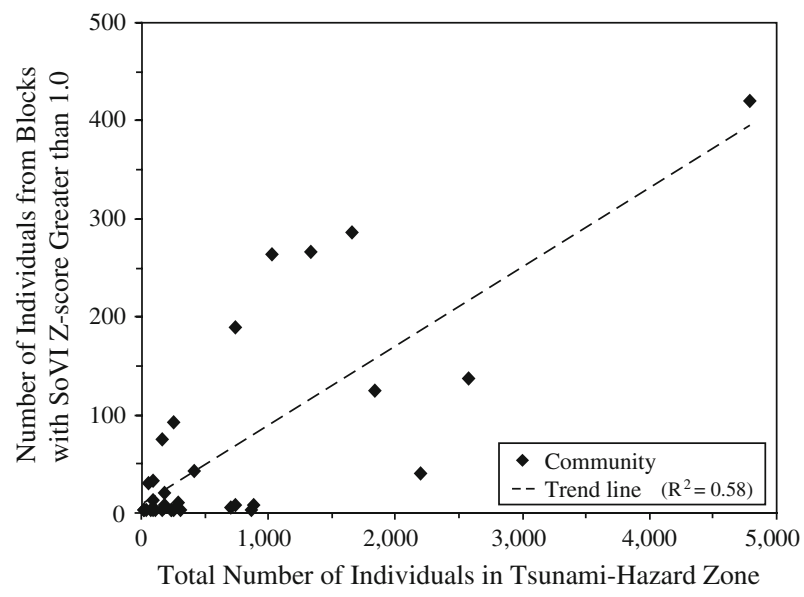

Fig. 5 Number of people in census blocks with SoVI scores greater than 1.0 compared to the total number of people in tsunami-hazard zone, summarized by Oregon city $(n=26)$

conditions and needs, using methods like those presented, when developing risk-reduction strategies and not to implement generic strategies with the assumption that all exposed populations in different cities along the Oregon coast have similar demographic compositions.

\section{Use and limitations of the SoVI approach}

The SoVI is designed to be a descriptive measure of social vulnerability to hazards based on exploratory factor analysis of demographic data. As demonstrated in the previous sections, the development and mapping of relative SoVI $z$-scores at the census-block level provides emergency managers with a mechanism for characterizing multivariate aspects of social vulnerability and for determining where local outliers exist across a region. The use of census blocks (the smallest geographic unit used by the U.S. Census Bureau) in this analysis may also minimize potential issues of ecological fallacy, where incorrect inferences about individuals are based on characteristics of the larger group to which they belong (Jones and Andrey 2007). While the potential for ecological fallacy remains, populations may become more homogenous as census units get smaller and variables that characterize average attributes of a population in a census block (e.g., per capita income, median rent, and number of persons per household) may better reflect all members of that census block than average attributes summarized at larger census units (e.g., tract or county).

Although SoVI scores can help emergency managers to identify outliers and their location across a landscape, they should not be construed as a complete characterization of social vulnerability in an area to a specific hazard. A principal component analysis may not always capture the dominant variables contributing to vulnerability, but rather those that best explain the variation in the input data (Jones and Andrey 2007). By normalizing raw census data to $z$-scores, the SoVI approach ignores differences in means among the original data and therefore focuses on variances, not regional conditions, in its relative assessment of social vulnerability across a study area. All variables, regardless of their original means 
and variance, are transformed to have zero means and a standard deviation of one. For example, if census block A has a value of $15 \%$ for the percentage of households that are renters $($ mean $=10 \%$, standard deviations $=1.5 \%)$ and census block $\mathrm{B}$ has a value of $95 \%$ for the percentage of residents over 65 years in age (mean $=90 \%$, standard deviations $=1.5 \%$ ), then the two blocks will have identical $z$-scores (3.33) for the different variables (i.e., 15 minus 10 divided by 1.5 equals 95 minus 90 divided 1.5). For these two variables, $z$-scores and subsequent SoVI scores may have similar patterns of data variability across a landscape, even though the second variable has a much higher mean before normalization. Therefore, the SoVI approach identifies variations in relative social vulnerability across a study and is not an exhaustive prioritized inventory of the primary causes of social vulnerability.

Since $z$-scores reflect the distance in standard deviations from the study-area mean, the distributions of two variables with drastically different standard deviations may also appear similar after their conversion to $z$-scores. For example, Fig. 6a shows a frequency histogram for the percentage of individuals in census blocks that are considered to be living in poverty $($ mean $=12.8 \%$, standard deviations $=6.5 \%$ ) and the percentage of individuals who are 65 years in age or greater $($ mean $=25.7 \%$, standard deviations $=25.9 \%$ ). Although the percentage of individuals who are 65 years in age or greater has a higher mean and a much greater range and distribution than the percentage of individuals living in poverty among the 2,086 census blocks (Fig. 2), its distribution of $z$-scores resembles those for the percentage of individuals living in poverty (Fig. 6b). Therefore, if emergency managers rely solely on results related to $z$-scores and do not also look at original data distributions, they may fail to realize that the large number of older residents may be a larger regional vulnerability issue than the smaller number of individuals living in poverty on the Oregon coast (Fig. 2).

The ability to use SoVI scores to identify hotspots of social vulnerability is immediately appealing to local managers who are responsible for site-specific risk-reduction efforts. State or regional emergency managers may want to first focus on variables that may not exhibit high variance, but that are consistently high across the region (especially those that are significantly higher than state and national averages), and then use block-level SoVI scores to find outliers. For example, Component 1 in our case study explained $9.7 \%$ of the

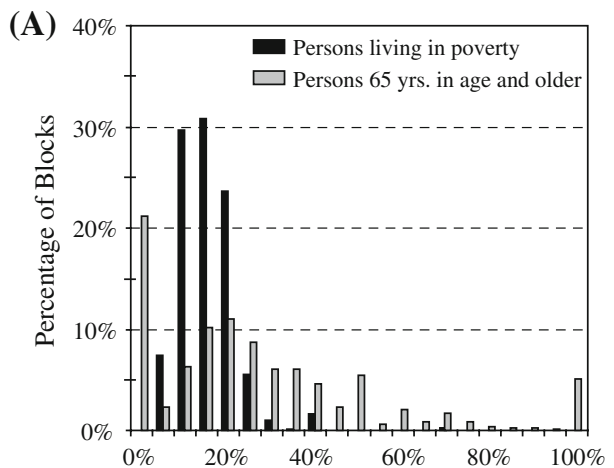

Percentage of Individuals in Census Block

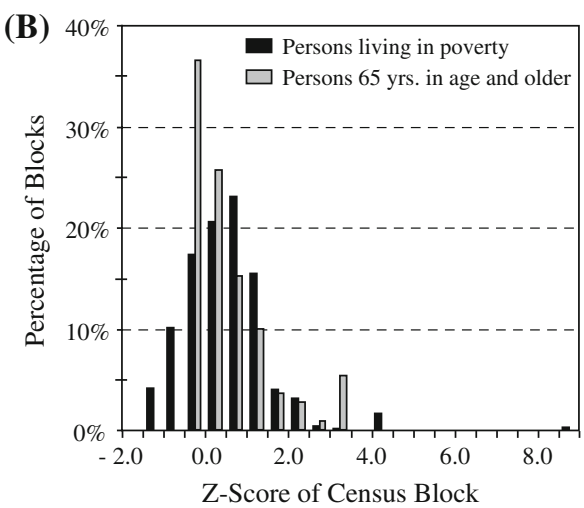

Fig. 6 Distribution of the percentage of individuals in census blocks who are considered to be living in poverty and the percentage of individuals who are 65 years in age or greater, portrayed as (a) the percentage of individuals in each census blocks and (b) the $z$-score of each census block 
variance and included variables relating wealth and education (e.g., persons living in poverty, persons 25 years in age or older with less than 12 years of education, and families earning $\$ 100,000$ or more), yet these variables all have means less than $15 \%$ of the population and are fairly close to national averages with standard deviations of approximately 5\% (Fig. 2). Other variables, such as the percent of individuals over 65 years in age (Component 2), the percent of housing units that are mobile homes (Component 4), and the percent of individuals receiving social security benefits (Component 5), have higher regional means and standard deviations than those in Component One and these means double national averages (Table 1). However, these variables load on components that explain less variance, and therefore have less weight, in final SoVI scores (Fig. 6). Therefore, a vulnerability analysis that relies only on SoVI will identify variables with high variance but may miss the aspects of demographic sensitivity that may show less variance but high initial percentages. For our case study of social vulnerability to tsunamis on the Oregon coast, these regional sensitivities include high percentages of the population that are over 65 years in age, are employed in primary industry and service occupations, live in mobile homes, or receive social security benefits. In each of these cases, study-area percentages of these variables are double the national averages, but these variables contribute less than other variables to overall database variance and weights to SoVI scores (Fig. 2).

Place-based context is considered an important element of understanding community vulnerability (Jones and Andrey 2007). In order to appreciate and characterize social vulnerability to a hazard, emergency managers should, therefore, calculate block-level SoVI scores and interpret them within the context of the original data and relative to the hazard in question. In doing so, emergency managers can determine regional conditions, identify site-specific outliers at the block level and where they exist across a region, and then determine the individual variables that are contributing to social vulnerability at that location. Once emergency managers have targeted highly vulnerable populations with additional risk-reduction strategies, they could work with social-service providers to address the non-hazard, socioeconomic conditions that create this vulnerability (e.g., poverty and lack of education). Methods and analysis presented here can be used not only for identifying immediate response needs to a specific threat (e.g., older populations needing assistance in evacuating tsunami-prone areas) but also for non-hazard issues of resource access (e.g., populations living in poverty needing assistance to recover) germane to any catastrophic event.

\section{Conclusions}

The impacts from a CSZ-related tsunami will be expressed differentially across communities along the Oregon coast. Certain individuals and groups within each community are likely to suffer disproportionately due to differences in socioeconomic conditions and other demographic attributes unrelated to the natural hazard. Emergency-management officials must understand not only the physical aspects of the tsunami threat in which currently a large body of knowledge exists, but also the oftentimes undocumented, place-based characteristics of the social environment. Of utmost significance relative to Cascadia tsunamis is the ability of emergency managers to identify those areas more susceptible to loss and those hosting populations that may need assistance in evacuating tsunami-prone areas or that lack in the ability to recover quickly following an event. Results presented here demonstrate that social vulnerability to Cascadia tsunami manifests itself differently throughout the study area and that the number of individuals in census blocks with high 
social vulnerability is not consistent across 26 cities. Methods presented here provide emergency managers with a process for characterizing the multivariate nature of residents and for identifying which communities have significant numbers of residents that may have high relative social vulnerability. This information provides emergency managers with the means to depart from one-size-fits-all mitigation strategies that inadequately address differences in social context and, instead, to develop strategies tailored to local conditions and needs.

Acknowledgments This study was supported by the U.S. Geological Survey (USGS) Geographic Analysis and Monitoring Program and a USGS and University of South Carolina, Department of Geography cooperative agreement (\#03HQAG0018), Multihazard vulnerability assessment decision support (sub agreement: \#0318HS004). We thank Susan Benjamin, Bryan Boruff, Lori Dinitz, Len Gaydos, Matt Schmidtlein, Mara Tongue, Tamara Wilson, Shelby Wood, and two anonymous reviewers for their insightful reviews of the earlier versions of the article.

Open Access This article is distributed under the terms of the Creative Commons Attribution Noncommercial License which permits any noncommercial use, distribution, and reproduction in any medium, provided the original author(s) and source are credited.

\section{References}

Adger W, Arnell N, Tompkins E (2005) Adapting to climate change-perspectives across scales. Glob Environ Change 15(2):75-76. doi:10.1016/j.gloenvcha.2005.03.001

Atwater B (1987) Evidence for great Holocene earthquakes along the outer coast of Washington State. Science 236:942-944. doi:10.1126/science.236.4804.942

Bateman J, Edwards B (2002) Gender and evacuation-a closer look at why women are more likely to evacuate for hurricanes. Nat Hazards Rev 3(3):107-117. doi:10.1061/(ASCE)1527-6988(2002) $3: 3(107)$

Bernard E (2005) The U.S. National Tsunami Hazard Mitigation Program-a successful State-Federal partnership. Nat Hazards 35:5-24. doi:10.1007/s11069-004-2401-5

Borden K, Schmidtlein M, Emrich C, Piegorsch W, Cutter S (2007) Vulnerability of U S cities to environmental hazards. J Homel Secur Emerg Manag 4(2):1-21

Boruff B, Cutter S (2007) The environmental vulnerability of Caribbean island nations. Geogr Rev 97(1):24-45

Boruff B, Emrich C, Cutter S (2005) Erosion hazard vulnerability of US coastal counties. J Coast Res 21(5):932-942. doi:10.2112/04-0172.1

Burby R, Steinberg L, Basolo V (2003) The tenure trap-the vulnerability of renters to joint natural and technological disasters. Urban Aff Rev 39(1):32-58. doi:10.1177/1078087403253053

Burton C, Cutter S (2008) Levee failures and social vulnerability in the Sacramento-San Joaquin Delta area, California. Nat Hazards Rev 9(3):136-149. doi:10.1061/(ASCE)1527-6988(2008)9:3(136)

Cascadia Region Earthquake Workgroup (2005) Cascadia subduction zone earthquakes—a magnitude 9.0 earthquake scenario. Oregon Department of Geology and Mineral Industries, Portland

Charland J, Priest G (1995) Inventory of critical and essential facilities vulnerable to earthquake and tsunami hazards on the Oregon coast. Oregon Department of Geology and Mineral Industries, Portland

Clark D, Davies W, Johnston R (1974) The application of factor analysis in human geography. Statistician 23(3/4):259-281. doi:10.2307/2987583

Clark G, Moser S, Ratick S, Dow K, Meyer W, Emani S, Jin W, Kasperson J, Kasperson R, Schwarz H (1998) Assessing the vulnerability of coastal communities to extreme storms: the case of Revere, MA, USA. Mitig Adapt Strateg Glob Chang 3:59-82

Cochrane H (1975) Natural hazards and their distributive effects. Institute of Behavioral Sciences, University of Colorado, Boulder

Cutter S (1996) Vulnerability to environmental hazards. Prog Hum Geogr 20(4):529-539. doi:10.1177/030 913259602000407

Cutter S (2001) American hazardscapes-the regionalization of hazards and disasters. Joseph Henry Press, Washington 
Cutter S (2003) The vulnerability of science and the science of vulnerability. Ann Assoc Am Geogr 93(1):112. doi:10.1111/1467-8306.93101

Cutter S, Finch C (2008) Temporal and spatial changes in social vulnerability to natural hazards. Proc Natl Acad Sci USA 105(7):2301-2306. doi:10.1073/pnas.0710375105

Cutter S, Mitchell J, Scott M (2000) Revealing the vulnerability of people and places - a case study of Georgetown County, South Carolina. Ann Assoc Am Geogr 90(4):713-737. doi:10.1111/00045608.00219

Cutter S, Boruff B, Shirley W (2003) Social vulnerability to environmental hazards. Soc Sci Q 84(1):242261. doi:10.1111/1540-6237.8402002

Cutter S, Emrich C, Mitchell J, Boruff B, Gall M, Schmidtlein M, Burton C, Melton G (2006) The long road home-race, class, and recovery from Hurricane Katrina. Environment 48(2):8-20

Dow K (1992) Exploring differences in our common future(s): the meaning of vulnerability to global environmental change. Geoforum 23:417-436. doi:10.1016/0016-7185(92)90052-6

Enarson E, Morrow B (1998) The gendered terrain of disaster. Praeger, Westport

Federal Emergency Management Agency (2001) State and local mitigation planning how-to guide No. 2understanding your risks: Federal Emergency Management Agency report no. 386-2, Available via http://www.fema.gov/library/viewRecord.do?id=1880. Accessed 21 Aug 2008

Gonzales F, Bernard E, Meinig C, Eble M, Mofjeld H, Stalin S (2005) The NTHMP tsunameter network. Nat Hazards 35:25-39. doi:10.1007/s11069-004-2402-4

H. John Heinz III Center for Science, Economics and the Environment (2000) The hidden costs of coastal hazards-implications for risk assessment and mitigation. Island Press, Covello

Hewitt K (1997) Regions of risk - a geographical introduction to disasters. Longman, Singapore

Johnston D, Paton D, Crawford G, Ronan K, Houghton B, Burgelt P (2005) Measuring tsunami preparedness in coastal Washington, United States. Nat Hazards 35(1):173-184. doi:10.1007/s11069-004-2419-8

Johnston D, Gregg C, Houghton B, Paton D, Leonard G, Garside R (2007) Developing warning and disaster response capacity in the tourism sector in coastal Washington, USA. Disaster Prev Manag 16(2):210216. doi: $10.1108 / 09653560710739531$

Jones B, Andrey J (2007) Vulnerability index construction: methodological choices and their influences on identifying vulnerable neighborhoods. Int J Emerg Manag 4(2):269-295

Laska S, Morrow B (2007) Social vulnerabilities and Hurricane Katrina-an unnatural disaster in New Orleans. Mar Technol Soc J 40(4):16-26

Lewis D (2007) Implementation of 2005 Senate Bill 2 relating to public safety, seismic safety and seismic rehabilitation of public buildings. Report to the Seventy-Fourth Oregon Legislative Assembly. Oregon Department of Geology and Mineral Industries, Portland

Mather P, Openshaw S (1974) Multivariate methods and geographical data. Statistician 23(3/4):283-308. doi: $10.2307 / 2987584$

McCreery C (2005) Impact of the National Tsunami Hazard Mitigation Program on operations of the Richard H. Hagemeyer Pacific Tsunami Warning Center. Nat Hazards 35:73-88. doi:10.1007/ s11069-004-2405-1

McGuire L, Ford E, Okoro C (2007) Natural disasters and older US adults with disabilities-implications for evacuation. Disasters 31(1):49-56. doi:10.1111/j.1467-7717.2007.00339.x

Mileti D (1999) Disasters by design—a reassessment of natural hazards in the United States. Joseph Henry Press, Washington

Morrow B (1999) Identifying and mapping community vulnerability. Disasters 23(1):1-18. doi:10.1111/ 1467-7717.00102

Myers E, Baptisa A, Priest G (1999) Finite element modeling of potential Cascadia subduction zone tsunamis. Sci Tsunami Hazards 17(1):3-18

Ngo E (2003) When disasters and age collide-reviewing vulnerability of the elderly. Nat Hazards Rev 2(2):80-89. doi:10.1061/(ASCE)1527-6988(2001)2:2(80)

Olmstead D (2003) Development in Oregon's tsunami inundation zone-information guide for developers and local government. Open-File Report OFR-03-05. Oregon Department of Geology and Mineral Industries, Portland

Oregon Department of Geology and Mineral Industries (2007) Tsunami maps and brochures. Available via http://www.oregongeology.com/sub/earthquakes/Coastal/Tsumaps.HTM. Accessed 20 Aug 2008

Oregon Department of Geology and Mineral Industries (2008) Oregon geology fact sheet-tsunami hazards in Oregon. DOGAMI Fact Sheet FS-3, 4 p. Available via http://www.oregongeology.org/pubs/ fs/tsunami-factsheet_onscreen.pdf. Accessed 25 Feb 2009

Oregon Geospatial Enterprise Office (2008) Tsunami inundation line. Available via Oregon Geospatial Enterprise Office (GEO) Spatial Data Library. http://gis.oregon.gov/DAS/EISPD/GEO/alphalist. shtml\#T. Accessed 20 Aug 2008 
Piegorsch W, Cutter S, Hardisty F (2007) Benchmark analysis for quantifying urban vulnerability to terrorist incidents. Risk Anal 27(6):1411-1425

Priest G (1995) Explanation of mapping methods and use of the tsunami hazard maps of the Oregon coast. Open-File Report O-95-67. State of Oregon Department of Geology and Mineral Industries, Portland

Priest G, Hull D, Vogt B, Karel A, Olmstead D (1996) Tsunami risk reduction-the Oregon strategy. Sci Tsunami Hazards 14(2):101-106

Priest G, Baptista A, Myers E III, Kamphaus R (2001) Tsunami hazard assessment in Oregon. In: Proceedings of international tsunami symposium 2001, National Tsunami Hazard Mitigation Program, pp 55-65

Rogers A, Walsh T, Kockelman W, Priest G (1996) Earthquake hazards in the Pacific Northwest-an overview. In: Rogers A, Walsh T, Kockelman W, Priest G (eds) Assessing earthquake hazards and reducing risk in the Pacific Northwest, U.S. Geological Survey Professional Paper 1560. Reston, Virginia, pp 1-54

Satake K, Shimazaki K, Tsuji K, Ueda K (1996) Time and size of a giant earthquake in Cascadiaearthquake inferred from Japanese tsunami records of January 1700. Nature 379:246-249. doi:10.1038/ 379246a0

Schmidtlein M, Deutsch R, Piegorsch W, Cutter S (2008) A sensitivity analysis of the Social Vulnerability Index. Risk Anal 28(4):1099-1114. doi:10.1111/j.1539-6924.2008.01072.x

Scott J (1975) Multivariate analysis in geography—some comments. Statistician 24(3):211-216. doi:10.2307/ 2987784

Tierney K, Lindell M, Perry R (2001) Facing the unexpected-disaster preparedness and response in the United States. Joseph Henry Press, Washington

Tobin G (1999) Sustainability and community resilience-the holy grail of hazards planning? Environ Hazards: Hum Policy Dimens, Glob Environ Chang Part B 1(1):13-25

Turner BII, Kasperson R, Matson P, McCarthy J, Corell R, Christensen L, Eckley N, Kasperson J, Luers A, Martello M, Polsky C, Pulsipher A, Schiller A (2003) Framework for vulnerability analysis in sustainability science. Proc Natl Acad Sci USA 100:8074-8079. doi:10.1073/pnas.1231335100

U.S. Census Bureau (2005) Cartographic boundary files. Available via http://www.census.gov/geo/www/ cob/pl_metadata.html. Accessed 27 Aug 2008

U.S. Census Bureau (2008) Census 2000. Census 2000 Gateway. Available via http://www.census.gov/ main/www/cen2000.html. Accessed 27 Aug 2008

U.S. Government Accountability Office (2006) U.S. Tsunami preparedness-Federal and State partners collaborate to help communities reduce potential impacts, but significant challenges remain. U.S. Government Accountability Office report no. GAO-06-519, Washington, DC

Walsh T, Meyers E III, Baptisa A (2003) Tsunami inundation map of the Neah Bay, Washington, area. Washington Division of Geology and Earth Resources Open-File Report 2003-2

Weichselgartner J (2001) Disaster mitigation - the concept of vulnerability revisited. Disaster Prev Manag 10(2):85-94. doi:10.1108/09653560110388609

Wisner B, Blaikie P, Cannon T, Davis I (2004) At risk-natural hazards, people's vulnerability and disasters, 2nd edn. Routledge, New York

Witter R (2008) Prehistoric Cascadia tsunami inundation and runup at Cannon Beach, Clatsop County, Oregon. Open-file Report O-08-12. Oregon Department of Geology and Mineral Industries, Portland

Witter R, Zhang Y, Priest G (2007) Testing numerical tsunami simulations against the extents of prehistoric Cascadia tsunami deposits at Cannon Beach, Oregon. San Francisco, CA, American Geophysical Union Fall Meeting Abstracts with Program

Wood N (2007) Variations in community exposure and sensitivity to tsunami hazards in Oregon. United States Geological Survey Scientific Investigations Report 2007-5283. Reston, Virginia

Wood N, Good J (2004) Vulnerability of a port and harbor community to earthquake and tsunami hazardsthe use of GIS in community hazard planning. Coast Manag 32(3):243-269. doi:10.1080/08920 750490448622

Wood N, Good J (2005) Perceptions of earthquake and tsunami issues in U.S. Pacific Northwest port and harbor communities. Int J Mass Emerg Disasters 23(3):103-138

Wood N, Soulard C (2008) Variations in community exposure and sensitivity to tsunami hazards on the open-ocean and Strait of Juan de Fuca coasts of Washington. United States Geological Survey Scientific Investigations Report 2008-5004. Reston, Virginia

Wood N, Good J, Goodwin R (2002) Vulnerability assessment of a port and harbor community to earthquake and tsunami hazards: integrating technical expert and stakeholder input. Nat Hazards Rev 3(4):148-157. doi:10.1061/(ASCE)1527-6988(2002)3:4(148)

Zhang Y, Baptista A, Wang K, Goldfinger C, Witter R, Priest G, Peterson C, Cruikshank K (2007) Hydrodynamic simulations of historic tsunamis from the Cascadia subduction zone: Portland, OR, Coastal Zone '07 Conference Extended Abstracts with Program 